\title{
Forehead versus nasolabial flaps for alar subunit reconstruction
}

\author{
Mohamed Ahmed Megahed, MD
}

\author{
Department of of Plastic Surgery, Menoufiya University, Egypt.
}

\begin{abstract}
Background: The reconstruction of full-thickness alar wounds often requires multiple challenging surgical procedures. These procedures, although often functionally and aesthetically successful, are often staged, and they therefore introduce operative risks, significant investments of surgeon and patient time, and extraordinary costs.

Aim of the work: Evaluation of the aesthetic and functional outcome, complications and donor site morbidity after alar reconstruction by paramedian forehead flap, two stage nasolabial flap and one stage nasolabial flap.

Patients \& methods: This research discusses the outcome of (27) patients after alar reconstruction: (11) patients with paramedian forehead flap, (9) patients with two stage nasolabial flap and (7) patients with one stage nasolabial flap. Conchal cartilage is used for reconstruction of the cartilagenous part of the alar subunit.

Results: Better results occur with nasolabial flap with best results with the one stage technique as regard the functional and aesthetic results and donor site morbidity.

Conclusion: More favourable aesthetic and functional results for alar subunit reconstruction occurred with the one stage nasolabial flap technique but when there is an associated other nasal subunit injuries, paramedian forehead flap and two stage nasolabial flap still have the best option.
\end{abstract}

Keywords: Alar subunit, reconstruction, flaps.

\section{Introduction:}

The nose is the most common site for cutaneous malignancy, and nasal defects requiring reconstruction frequently result from tumor resection. These defects present both a functional and an aesthetic challenge to the surgeon. The ala is a unique structure that plays a key role in the airway as well as in the harmony of nasal geometry. Because it is a paired structure, the restoration of the premorbid aesthetic and anatomic state of the ala is crucial in achieving an optimal result. ${ }^{1}$

Nasal reconstruction remains one of the most challenging aspects of facial plastic surgery. Considerations of complex skin contours, cutaneous color, and texture take on unique nuances when trying to achieve a functional airway overlaying a 3-dimensional structural framework. Because of limited local or adjacent tissue useful for reconstruction, regional interpolated flaps have become the mainstay of inferior-third nasal reconstruction procedures. The nasal ala, borded laterally by the alar groove, medially by the nasal tip, and superiorly by the nasal sidewall and adjoining the nasojugal crease, poses unique reconstruction challenges. Commonly, the paramedian forehead flap allows for superb alar reconstruction, yet it requires a second stage and an intervening period during which the pedicle can be troublesome to many patients. $^{2}$

Alternatively, the melolabial flap can provide an excellent reconstruction of even full-thickness alar defects up to $2.5 \mathrm{~cm}$ in width with a single stage. ${ }^{3}$ The melolabial region is made of cheek tissue surrounding the melolabial crease from the ala to the oral commissure. Sometimes referred to as nasolabial, melolabial is an anatomically more precise description. ${ }^{3}$ Historically, the melolabial flap has most frequently been used as a 2-stage procedure. ${ }^{5,6}$ It may be that the fairly high reported incidence of pin-cushioning and 
trapdoor formation with the pedicled technique has resulted in the melolabial flap often being considered a secondary choice in alar reconstruction. ${ }^{7}$ As a single-staged procedure, however, we have found alar reconstruction success not limited by these drawbacks.

\section{Aim of the work:}

Evaluation of the aesthetic and functional outcome, complications and donor site morbidity after alar reconstruction by paramedian forehead flap, two stage nasolabial flap and one stage nasolabial flap.

\section{Patients and methods:}

This research discusses the outcome of 27 patients with alar defects; 18 males and 9 females, age ranges (18-76 years old), operated in Menoufiya University Hospitals from October 2007 to August 2009. Follow up period for 6 months. 16 patients were complaining of cutaneous nasal malignancy, 7 patients were complaining of traumatic alar defects and 4 patients were complaining of postburn alar defects. After patients consent the following variables were recorded from the medical record; age, sex, occupation, habits, medical history, complications, tumor type or defect size, flap type, pre and post operative photographic documentation and number of procedures. The aesthetic outcome was evaluated regarding alar contour, alar groove, colour matching, donor site scar and symmetry. The results were judged as excellent, good, fair by the final photograph, doctor and patient satisfaction.

\section{Surgical technique:}

Patients were divided into three groups; Group (I): 11 patients reconstructed by paramedian forehead flap, Group (II): 9 patients reconstructed by two stage nasolabial flap and Group (III): 7 patients reconstructed by one stage nasolabial flap. Under general anesthesia and positioning of the patient $45^{\circ}$ head up \& sterilization tumor and burn contracture excision or defect refreshment was done. Full thickness skin graft or vestibular skin flap were transposed to close the inner alar defect then conchal cartilage graft is sutured to the edges of the defect to perform the alar contour then flap design and reconstruction done.

\section{Paramedian forehead flap:}

When a forehead flap is used as the covering flap, a template of the defect is placed just inferior to the hairline and centered over the vertical distribution of the ipsilateral supratrochlear artery. The artery arises at approximately the level of the medial aspect of the brow-corrugator crease line. In those patients with a low anterior hairline, part of the template may need to be in the hair-bearing scalp or directed obliquely to avoid hair-bearing skin. The template is then traced on the forehead, and vertical limbs are drawn downward from the template to encompass a $1.5 \mathrm{~cm}$ wide pedicle centered on the medial brow-corrugator crease. If extra length is required, the pedicle may extend into or below the medial brow. The flap is incised and mobilized inferiorly until a relative tensionfree closure can be obtained. The flap is sutured to the nasal skin, everting the wound edges using vertical mattress sutures. The forehead skin is widely undermined in the subgaleal plane and the donor site wound is closed in layers. Flap separation and refashioning is done 3 weeks later.

\section{Two stage nasolabial flap:}

The anatomy of the nasolabial fold area allows for 180-degree rotation of the flap for transfer to the defect. Facial and angular artery branches perforate the levator labii muscle near the ala and travel across the cheek. The superior subcutaneous base of the flap has an abundant blood supply from the perforators, and the skin pedicle can be tapered to a point at the junction of the lip, cheek, and alar groove. The flap is designed just above the nasolabial crease on the side of the defect and the donor site is closed in the line of the nasolabial crease. A dog-ear is excised distally once the pattern of the defect has been traced to the nasolabial fold flap. The flap is designed $1 \mathrm{~mm}$ larger than the defect to account for contracture. The distal flap is thinned to $5 \mathrm{~mm}$ prior to inset. Undermining the cheek for approximately $3.5 \mathrm{~cm}$ laterally closes the donor site. The cheek is advanced medially and superiorly.

The second stage, which can be safely performed at 10 to 14 days, entails division of the pedicle. The tapered base of the flap is detached from the cheek and thinned and 
wrapped around to form the alar base and nostril sill if the entire ala is involved or if the remaining normal alar skin is excised.

\section{One stage nasolabial flap:}

The melolabial flap design in this reconstructive series functions as a superiorly based random-pattern transpositionadvancement flap. Its blood supply is random, although usually quite redundant, on multiple perforating branches of the distal facial and angular arteries perforating through the levator labii musculature. Drainage proceeds to the facial vein. Sensory innervation comes from the infraorbital and mentalis branches of the trigeminal nerve.

In preparation for flap design, the alar defect is measured and then lateral nasal tissue between the nasofacial border and the defect is removed. The tissue excised will be a trapezoidal shape, from defect to nasojugal crease, precisely the maximum of $30^{\circ}$ to eliminate a standing cone at the point of rotation and avoid compromise of blood supply to the melolabial flap. This facilitates a single-stage melolabial flap transfer. The medial aspect of the melolabial flap corresponds to the melolabial crease itself, and the most distal aspect of the flap should allow for a tapering $30^{\circ}$ point. The lateral cheek incision should be placed precisely the width of the defect (when rotation is considered) lateral to the nasojugal

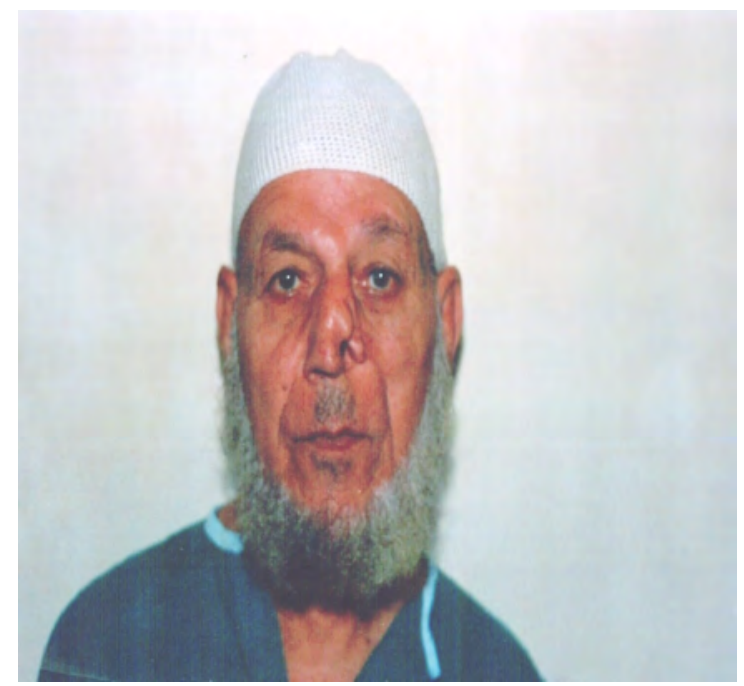

Figure (1): Preoperative after traumatic alar defect. sulcus and medial to the melolabial incision line. The lateral cheek incision should extend no higher than the point at which the nasal defect meets the nasojugal crease. This ensures a wide vascular base for the donor flap. Adequate flap length will be required for alar reconstruction. The distance from the point of rotation to the distal defect should be maintained before tapering.

The flap is elevated defatted and then advanced medially, transposing the flap into the nasal defect over a peninsula of remaining alar skin. Plication of the cheek superficial musculoaponeurotic system facilitates a tension-free advancement and a tension-free closure of the donor site. The nasojugal sulcus is then reconstructed with 2 buried permanent clear nylon sutures from the deep flap to flap to the piriform aperture periosteum. Tightening of the suture pulls the flap medially and holds it down into the concave nasojugal sulcus, restoring the normal contour and minimizing wound tension. As the donor site is closed, care is taken to avoid overeversion of the melolabial crease.

Wide undermining of the entire nasal tip and dorsum along with the cheek facilitates an easy tension-free closure and limits pincushioning and trapdoor formation. The distal flap is then thinned aggressively. Fat transposed with the flap tends to fibrose and contract, lending itself to trapdoor formation.

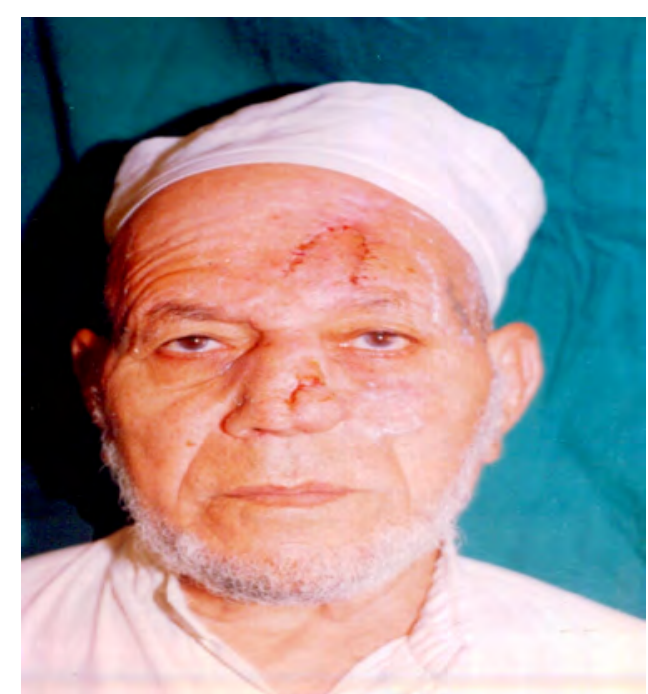

Figure (2): Postoperative after forehead flap. 


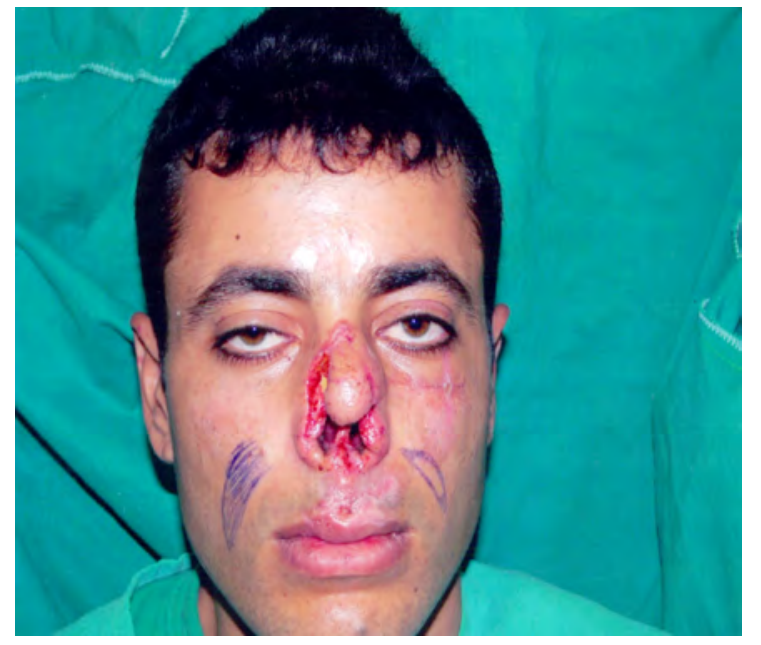

Figure (3): Preoperative after nasal trauma.

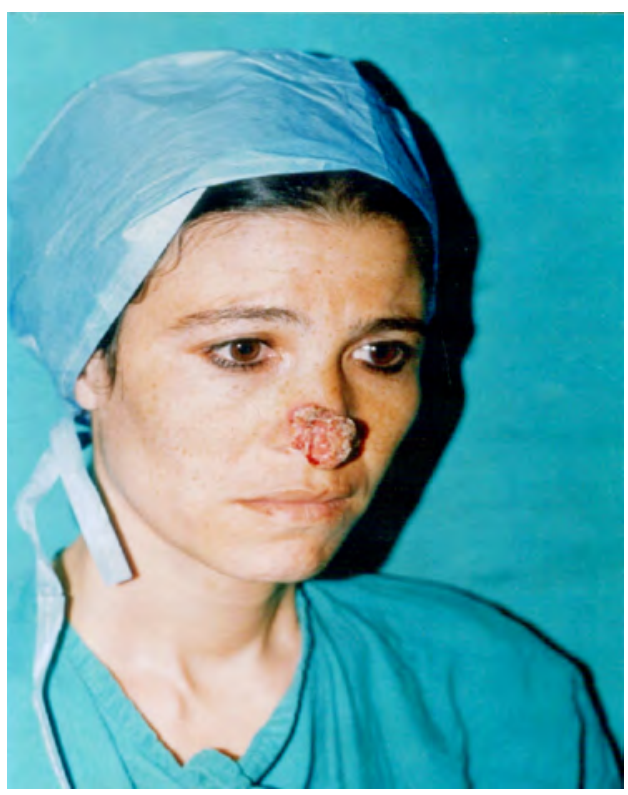

Figure (5): Preoperative squamous cell carcinoma of the nose.

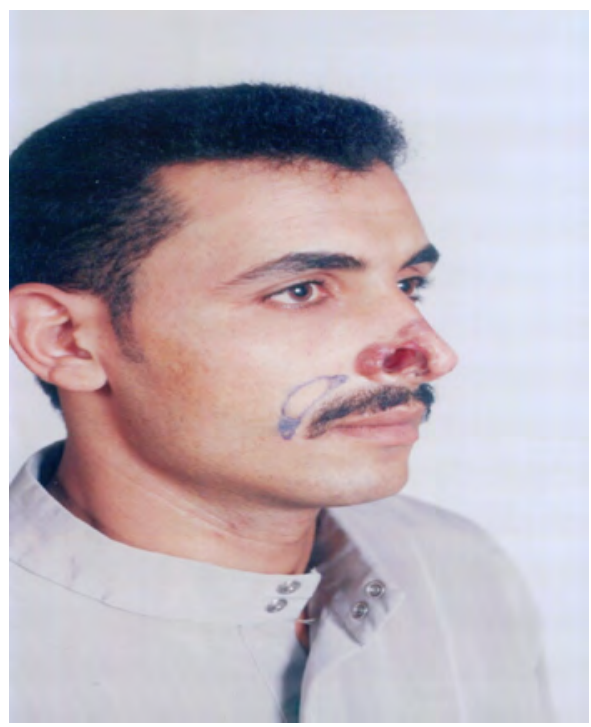

Figure (7): Preoperative after nasal trauma.

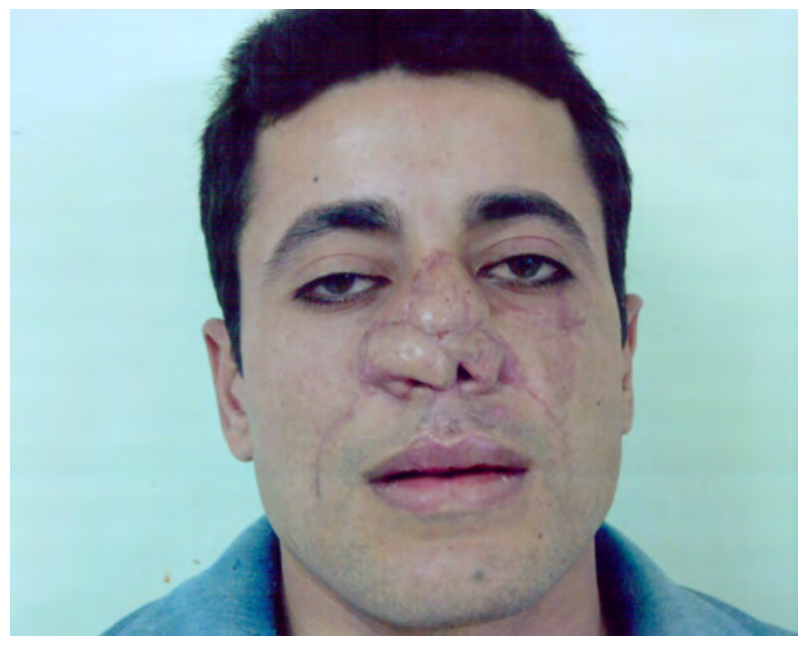

Figure (4): Postoperative after bilateral two stage nasolabial flap.

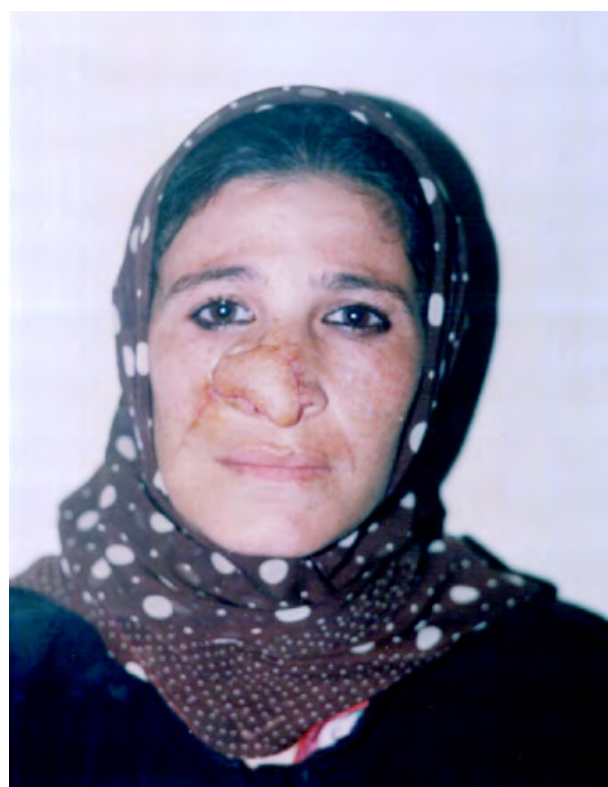

Figure (6): Postoperative after two stages nasolabial flap reconstruction.

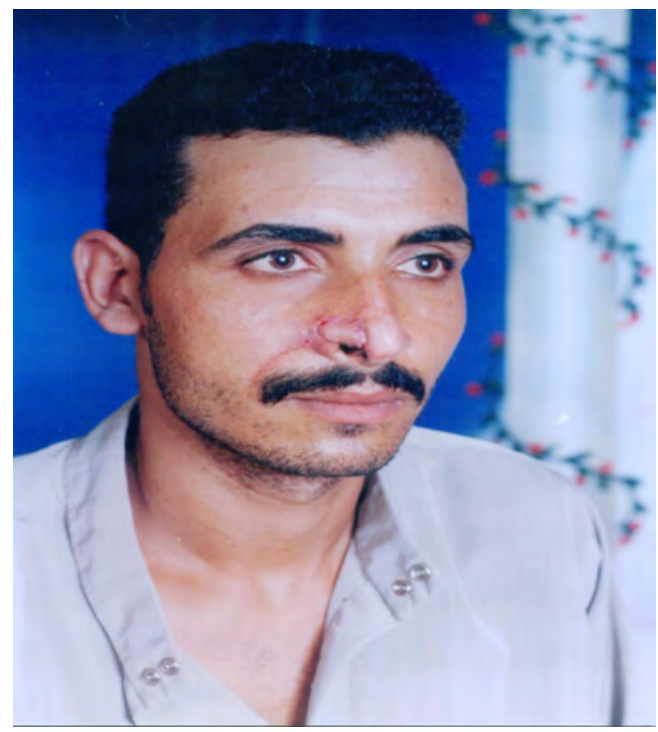

Figure (8): Postoperative after one stage nasolabial flap. 


\section{Results:}

During the past 2 years, 27 patients; 18 males and 9 females age ranges (18-76 years old) had undergone reconstruction of the alar subunit using paramedian forehead flap (11) patients, two stage nasolabial flap (9) patients and one stage nasolabial flap (7) patients. Also, free conchal cartilage flap used to support the alar contour and vestibular skin or full thickness skin graft as inner lining Tables(1,2).

\section{Group (I) Figures(1,2):}

Eleven patients with alar subunit defects were reconstructed by paramedian forehead flap with minor complications in the form of infection in one case and wound dehesince in one case that were treated conservatively while two cases of partial flap loss occurred in smokers. One of them was managed conservatively by excision and direct closure while the other needed small full thickness graft. One case suffered from total flap loss which occurred in an old diabetic patient and was managed by nasolabial flap. Four patients were not satisfied with the donor site scar but 7 patients were satisfied with the results.

\section{Group (II) Figures(3,4,5,6):}

Nine patients with alar subunit defects were reconstructed by two stage nasolabial flap with minor complications in the form of infection in one case that was managed conservatively. There was no total flap loss but there were two cases of partial flap loss that were managed by full thickness skin graft. In one case of bilateral nasolabial flap alar reconstruction and vestibular stenosis occurred and was managed by costal cartilage to support the anterior nasal septum. Z. plasty \& debulking of the flap were done. Six patients were satisfied with the results.

\section{Group (III) Figures(7,8):}

Seven patients with alar subunit defects were reconstructed by one stage nasolabial flap. In one case, partial flap loss occured and was managed conservatively by direct closure (in patient with ischemic heart disease). Aesthetic results were excellent and 6 patients were satisfied with the results of the one stage procedure.

Table (1): Aesthetic results as regard the three techniques.

\begin{tabular}{|c|c|c|c|}
\hline $\begin{array}{l}\text { Technique } \\
\text { Aesthetic } \\
\text { variables }\end{array}$ & $\begin{array}{l}\text { Forehead flap } \\
\text { (11) patients }\end{array}$ & $\begin{array}{c}\text { Two stage nasolabial flap } \\
\text { (9) patients }\end{array}$ & $\begin{array}{l}\text { One stage nasolabial flap } \\
\text { (7) patients }\end{array}$ \\
\hline Alar contour & Good & Good & Excellent \\
\hline Alar groove & Good & Fair & Excellent \\
\hline Colour matching & Good & Excellent & Excellent \\
\hline Donor site scar & Fair & Good & Excellent \\
\hline Symmetry & Excellent & Fair & Excellent \\
\hline Patient satisfaction & $63 \%$ & $66 \%$ & $85 \%$ \\
\hline
\end{tabular}


Table (2): Complications as regard the three techniques.

\begin{tabular}{|c|c|c|c|c|c|c|}
\hline \multirow{2}{*}{ Complications } & \multicolumn{2}{|c|}{$\begin{array}{l}\text { Forehead flap } \\
\text { (11) patients }\end{array}$} & \multicolumn{2}{|c|}{$\begin{array}{l}\text { Two stage nasolabial flap } \\
\text { (9) patients }\end{array}$} & \multicolumn{2}{|c|}{$\begin{array}{l}\text { One stage nasolabial flap } \\
\text { (7) patients }\end{array}$} \\
\hline & No. & $\%$ & No. & $\%$ & No. & $\%$ \\
\hline Infection & 1 & $9 \%$ & 1 & $11 \%$ & 0 & $0 \%$ \\
\hline Bleeding & 0 & $0 \%$ & 0 & $0 \%$ & 0 & $0 \%$ \\
\hline Wound dehiscence & 1 & $9 \%$ & 0 & $0 \%$ & 0 & $0 \%$ \\
\hline Partial flap loss & 2 & $18.2 \%$ & 2 & $22 \%$ & 1 & $14 \%$ \\
\hline Total flap loss & 1 & $9 \%$ & 0 & $0 \%$ & 0 & $0 \%$ \\
\hline
\end{tabular}

\section{Discussion:}

Nasal reconstruction remains one of the most challenging areas of facial plastic surgery. Although the forehead flap is the workhorse technique for repairing complex tissue losses involving multiple nasal subunits, for defects of limited size, the nasolabial flap can provide equal or superior results in a single stage. ${ }^{8}$

Reconstruction of the nasal ala is a complex task. Burget ${ }^{9}$ has outlined 7 principles unique to aesthetic reconstruction of the face. These are as follows: (1) The goal is normal facial contour. (2) The missing part is restored in its 3-dimensional form replacing each layer with like tissue. (3) Templates are used for the design of grafts and flaps. (4) Donor scars should be hidden or camouflaged. (5) Replace the entire nasal aesthetic unit when practical. (6) Use cartilage grafts to create contour, prevent collapse, and resist the forces of contraction. (7) Use subcutaneous sculpturing to refine the result.

This research discusses the outcome of 27 patients of alar reconstruction and the early experience with single stage nasolabial transposition flap has confirmed the task of these 7 principles of alar reconstruction and most patients were satisfied with this one stage technique and these results coincide with that of Drisco and Baker. ${ }^{10}$

The selection of a forehead or two stage nasolabial flap is primarily based on the size of the defect and associated other nasal subunit injury like side walls or nasal tip. Another relative indication for the forehead flap is young patient with little cheek laxity and less nasolabial folds.

For aesthetic purposes in this research, colour and tissue matching and scar were better after nasolabial flap than forehead flap and this result coincides with Arden et al. ${ }^{8}$ who reported that objectively rated tissue match and found the melolabial flap superior. Interestingly, they also evaluated scar length and width for the 2 procedures and believed that the melolabial scar was more acceptable. They reported that 1 of 3 patients was dissatisfied with the forehead scar result.

While, Burget ${ }^{9}$ reported that in single subunit alar losses, however, the selection process may be tempered by anatomic features and lifestyle choices of the patient. In a younger patient with a shallow or poorly developed melolabial crease, who chooses a hairstyle with bangs, a paramedian flap wound offer better scar camouflage.

In this research as regard nasofacial groove and symmetry, forehead flap and one stage nasolabial flap gave the best results. Drisco and Baker ${ }^{10}$ clarify that these results to the trained eye, almost all cheek flaps result in some asymmetry of the melolabial folds. The typical stigmata is flattening of the inferior aspect of the melolabial fold in all patients along with enhanced fullness of the superiorly in some. These problems can be improved with revision surgery or excision of the contralateral melolabial fold. 
As regard the patient satisfaction, best results were attained with the one stage nasolabial flap $(85 \%)$ rather than two stage nasolabial flap $(66 \%)$ or the forehead flap $(63 \%)$. This is because this technique is a one stage procedure and fulfilled the 7 principles of Burget ${ }^{9}$ for aesthetic reconstruction of the face.

\section{Conclusion:}

More favourable aesthetic and functional results for alar subunit reconstruction occurred with the one stage nasolabial flap technique but when there is an associated other nasal subunit injuries, paramedian forehead flap and two stage nasolabial flap still have the best option.

\section{References:}

1- Singh DJ, Bartlett SP: Nasal reconstruction: Aesthetic and functional considerations for alar defects. Facial Plast Surg 2003; 19(1): 19-27.

2- Lindsey WH: Reliability of the melolabial flap for alar reconstruction. Arch Fac Plas Surg 2001; 3(1): 33-37.
3- Zitelli JA: The nasolabial flap as a singlestage procedure. Arch Dermatol 1990; 126: 1445-1448.

4- Younger RAL: The versatile melolabial flap. Otolaryngol Head Neck Surg 1992; 107: 721-726.

5- Humphries TR, Goldberg LH, Wiemer DR: Repair of defects of the nasal ala. Dermatol Surg 1997; 23: 335-349.

6- Becker FF, Johns Langford FP: Local flaps in nasal reconstruction. Fac Plast Clin North Am 1996; 4: 505-515.

7- Zitelli JA, Fazio MJ: Reconstruction of the nose with local flaps. J Dermatol Surg Oncol 1991; 17: 184-189.

8- Arden RL, Nawroz-Danish M, Yoo GH, Meleca RJ, Burgio DL: Nasal alar reconstruction. A critical analysis using melolabial island and paramedian forehead flaps. Laryngoscope 1999; 109(3): 376382.

9- Burget GC: Aesthetic restoration of the nose. Clin Plast Surg 1985; 12: 463-480.

10-Drisco BP, Baker SR: Reconstruction of nasal alar defects. Arch Fac Plas Surg 2001; 3(2): 91-99. 